NASA Technical Memorandum 102548

\title{
Electromechanical Actuation for Thrust Vector Control Applications
}

Mary Ellen Roth

Lewis Research Center

Cleveland, Ohio

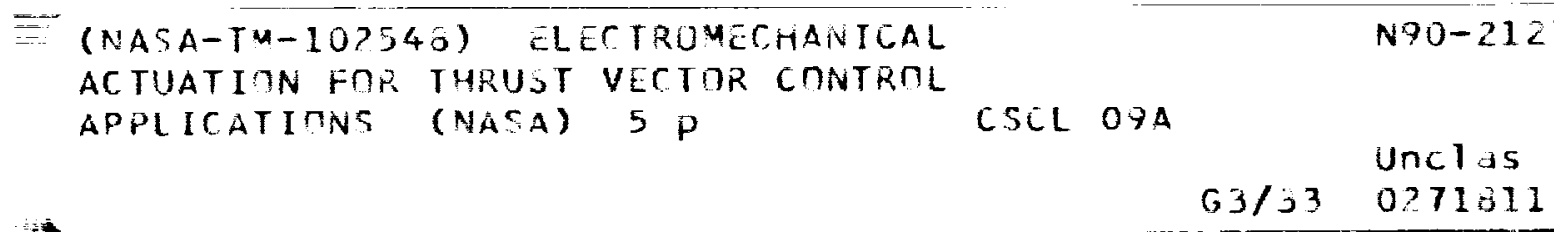

Prepared for the

National Aerospace and Electronics Conference (NAECON) sponsored by the Institute of Electrical and Electronics Engineers

Dayton, Ohio, May 21-25, 1990

\section{N/SA}




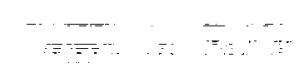




\author{
Mary Ellen Roth \\ National Aeronautics and Space Administration \\ Lewts Research Center \\ Cleveland, Ohio 44135
}

\section{ABSTRACT}

At present, actuation systems for the Thrust vector control (TVC) for launch vehicles are hydraulic systems. The Advanced Launch System (ALS), a joint initlative between NASA and the AIr Force, is a launch vehicle that is designed to be cost effective, highly rellable and operationaliy efficlent with a goal of reducing the cost per pound to orblt. As part of this initlative, an electromechantcal actuation system is being developed as an attractive alternative to the hydrauilc systems used today.

The NASA Lewis Research Center is developing and demonstrating an Induction Motor Controller Actuation System with a 40 hp peak rating. The controller will integrate $20 \mathrm{kHz}$ resonant 1 Ink Power Management and Distribution (PMAD) technology and Pulse Population Modulation (PPM) techniques to implement Fleld oriented Vector control (FOVC) of a new advanced induction motor. Through PPM, multiphase varlable frequency, varlable voltage waveforms can be synthesized from the $20 \mathrm{kHz}$ source. FOVC shows that varying both the voltage and frequency and their ratio ( $V / F)$, permits independent control of both torque and speed while operating at maximum efficiency at any point on the torque-speed curve. The driver and the FOVC will be microprocessor controlled. For increased system reliability, a Built-in Test (BITE) capability will be included. This involves Introducing testability into the design of a system such that testing is calibrated and exercised during the design, manufacturing. maintenance and pre-launch activities. An actuator will be integrated with the motor controller for performance testing of the EMA TVC system. The design and fabrication of the motor controller is being done by General Dynamics Space Systems Division. The University of Wisconsin - Madison wlll assist in the design of the advanced induction motor and in the implementation of the FOVC theory. A 75 hp electronically controlled dynamometer wili be used to test the motor controller in all four quadrants of operation using flight type control algorlthms. Integrated testing of the controiler and actuator will be conducted at a facllity yet to be named. This paper will discuss, in detail, the EMA system described above.

\section{INTRODUCTION}

Today Thrust Vector Control (TVC) Actuation systems for launch vehicles are typically hydraulic systems. Electromechanical actuation offers an attractive alternative to the hydraulle systems. NASA Lewis Research Center is developing and demonstrating an Induction Motor Controller Actuation System, with a 40 hp peak capabllity. The motor controller will integrate $20 \mathrm{kHz}$ resonant 1 ink Power Management and Distribution (PMAD) technology and Pulse Population Modulation (PPM) technique to implement Field Oriented vector control of a new advanced induction motor. An actuator will be integrated with the motor controller for performance testing of the EMA TVC system. The design and fabrication of the controller and actuatorcontroller integration is being done by General

* NASA Lewis Research Center Task Order Contract NAS3-25799.
Dynamics Space Systems Division in San Diego, under task order contract." The University of Wisconsin Madlson will assist in the design of the advanced induction motor and in the implementation of the FOVC theory. Testing of the EMA TVC system will be conducted by the government at a faclllty yet to be determined. This paper will discuss the work already completed and what is proposed for the future.

\section{EMA TVC SYSTEM OPERATIONAL REQUIREMENTS}

Launch vehicle TVC systems typically operate at a moderate continuous power level except for three brlef perlods. of the order of a few seconds, where peaks in excess of several times the continuous rating are required. These peaks occur at lift-off, max-Q and cargo separation, as deplcted in figure $i$. An actuation system must deliver the required peak power and still operate efficientiy at its continuous rating. The EMA system being developed is deslgned to meet these operational characteristics, with a high degree of rellabllity. without the expenses of being overdesigned. The system block diagram is shown in figure 2.

Some design objectives to meet these requirements are the following: reduce the size of the electronics in the driver and the controls, design and develop an advanced induction motor for this specific application. implement advanced control of the motor. implement a Built-in Test capablitity for increased system relfability, through redundancy management and simplified checkouts to verify system operation. The various design approaches taken to meet these objectives are further discussed throughout this paper.

\section{ORIVER DESIGN AND SIZING CONSIDERATIONS}

In the state-of-the-art for EMA systems, the motor driver is typically many times larger than the motor. This is mainly due to the size of the power electronics and the cholce of modulation techniques for synthesis of the machine frequency waveforms. This size problem has been, in the past, one prime reason why this technology has not been the one of cholce for TVC systems. The EMA system being developed is sensitive to this issue and is designed to overcome this problem. As shown in figure 2, the induction motor is driven from a $20 \mathrm{kHz}$ link. The link input inverter can accept el ther dc or ac input. The motor driver uses PPM techniques to synthesize the lower frequency waveforms needed to drive the motor ( $f(g, 3)$. The output of the driver is a three-phase set of variable frequency, variable voltage waveforms controllable from 0 to $500 \mathrm{~V}$ ac, 0 to $1000 \mathrm{~Hz}$. PPM has several advantages over the Pulse Width Modulation schemes often selected for such applications. With PPM, all switching is done at zerocrossing, minimizing the stress on the switching devices and reducing their associated losses. The switching is done at the carrier frequency $(20 \mathrm{kHz})$ not the machine frequency. Consequentiy, the size of the associated electronlc storage elements is reduced. This technique results in a much cleaner system, putting little nolse back on the power bus--a problem common to PWM systems.

The switch of choice for the current design of the driver is the IGBT. The IGBT has a greater current 
density than other readily avallable power semiconductors and requires a much lower powered gate drive signa) than its counterparts. Symmetrical MCT's, now under development, will be utillzed when they become available. The MCT offers a much lower forward drop (c) $V$ ) than the ICBT. More Importantly, its forward drop 15 independent of the current. The symmetrical MCT, a true ac switch. whll help in reducing the size of the electronics as well. The ultimate goal is for the electronics to be comparable in size or smaller than the motor. Whlle this will not be fully accomplished on this contract, the controller will be packaged in a manner to demonstrate that further size reduction in both the electronics and controls is feaslble.

\section{FIELO ORIENTED VECTOR CONTROL}

The project objectlve to design a 40 hp (peak) driver and minimize the size of the driver, has resulted in a design that makes the maximum utlilization of the electronics within their current limits. Consequentiy. the motor must be operated at its maximum efficiency at all times if the system is to deliver the peak power required. This is accomplished through a Fleld Orlented Vector Control approach based on the work done at the University of WIsconsin (LIpo and SUI, 1988). FOVC theory states that the stator current can be broken down into two or thogonal vector currents, a torque producing current and a flux producing current. These currents are controlled independently by varying the stator applled voltage and frequency. This permits independent control of both the torque and speed. The motor can produce its maximum torque at any speed, including stall (Hansen, 1990). In addition, by varying the voltage to frequency ratio, the motor can be operated at its maximum efflclency at any point on the torque-speed curve. By varying this ratio, the flux level of the machine is controlled. There is a distinct advantage to operating the motor at reduced flux levels during extended perfods where only minimal power levels are required (Lorenz and Yang, 1989). All of this capability is implemented through microprocessor control.

\section{ADVANCED INDUCTION MOTOR}

The induction motor was selected for the EMA system due to its inherent rugged and simple construction. It has a higher potential operating temperature ( $>200^{\circ} \mathrm{C}$ ) than a permanent magnet motor and has a high peak torque capablilty. This peak torque capability is most important for an EMA application such as this.

Because little emphasls has been placed by industry on designing a better induction motor, considerable effort is belng expended under this contract to design and develop an advanced induction motor. The goal of this effort is to produce a design that is sensitive to the requirements for this specific application. The design will bulid upon the induction motor's inherent strengths and also minimizes some of its weaknesses when compared to a permanent magnet or switched reluctance motor. For this application, it is not the steady state horsepower rating that is most important. but the torque output of the motor and the removal of heat at the peak torque demands. The new design wlll focus on these characteristics. The advanced motor will probably utilize high permeability materlals, such as supermandeur. Such materlals will minimize saturation and the consequent increase in leakage reactance of the motor and thus improve its peak torque capabllity. A low resistance rotor will reduce the losses in the rotor as compared to typical induction motors. The motor will be designed to operate at low sllo and to meet a thermal requirement of $200^{\circ} \mathrm{C}$ operation.

\section{BUILT-IN TEST}

Increased system level reliabllity and zero-defect components are desirable attributes of any system. This is espectally important in a TVC system because a rellable system saves both money and manhours, thereby contributing to the reduction of the cost per pound to orbit. The concept of Bulit-in Test (BITE) involves introducing testabllity into the design of a system or component such that the testing is callbrated and exerclsed during design, manufacture, maintenance and prelaunch activities. Unllke most checkout or callibration procedures, this is done in parallel with normal system operation. The objective is to monitor the fewest number of parameters that will provide adequate information for determining the status and health of the system. This work is just beginning. Items that are being addressed include: (1) What parameters should be monitored; (2) How to implement this testability into the malntenance and production activities: (3) How to implement continuous monitoring during prelaunch: (4) How to use the microprocessor which is controlling the driver to also control the BITE functions; and (5) How rellablilty of the system is effected by the additional circuitry that is dedicated to BITE functions. The BITE feature will not be implemented into the TVC at this early stage of the contract.

\section{SYSTEM VERIFICATION}

The testing program will be divided into two phases. For Phase I, the Induction Motor Controller (excluding the actuator) will be tested to demonstrate four-quadrant operation at full power. A 75 hp electronically controlled dynamometer will be used to verify controller operation in both the generating and motoring modes using flight-type control algorithms. This testing will be conducted at GDSS in San Diego, CA. In Phase II, integrated testing (motor controller and actuator) wfil be conducted by the government at another facllity. Candidate facilities include Wright Patterson Alr Force Base and NASA-MSFC, Huntsville, pending arrangements. The testing program is expected to be completed by mid-1991.

\section{CONCLUSION}

The purpose of this task order contract is to demonstrate that the electromechanical thrust vector control technology is a mature technology with marked advantages over present TVC systems. The EMA system proposed integrates $20 \mathrm{kHz}$ resonant 1 ink PMAD technology and PPM to implement Field Oriented Vector Control of an advanced induction motor. The system includes a BITE capability for health and status monitoring resulting in increased system rellability. An EMA system. such as the one described, in the range of $40 \mathrm{hp}$ is sufficlent to power most TVC applications as well as control surface actuators. A thorough and rigorous testing program is planned to verify and demonstrate system operation. A successful demonstration of this technology would verify significant advances in aeronautical (commerclal and military alrplanes), aerospace, NTS (shuttle) or NASP applications of Electromechanical Actuation. 


\section{REFERENCES}

1. Lipo, T. A.; and Sul, S. K.: Field Oriented Control of an Induction Machine in a High Frequency Link Power System. Research Report 88-4, NASA Contract NAG3-786, Jan. 1988.

2. Hansen, I. G.: Aerospace Induction Motor Actuators Driven from a $20 \mathrm{kHz}$ Link. Fourth International Con-

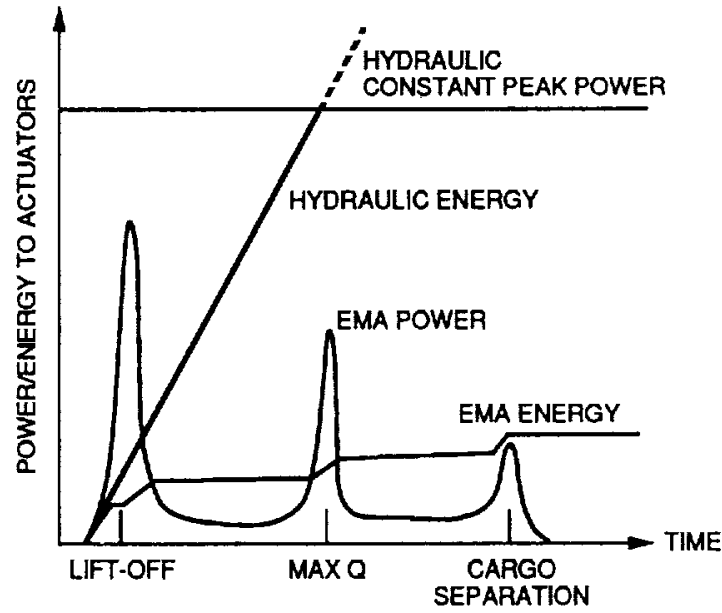

Figure 1. - Power/energy flight profile. ference on Power Electronics and Variable Speed

orives. July 1990.

3. Lorenz, R. D.: Yang, S. M.: AC Induction Servo Sizing for Motion Control Applications Via Loss Minimizing Real-Time Flux Control. Wisconsin Electric Machines and Power Electronics Consortium Research Report 89-18, June 1989.

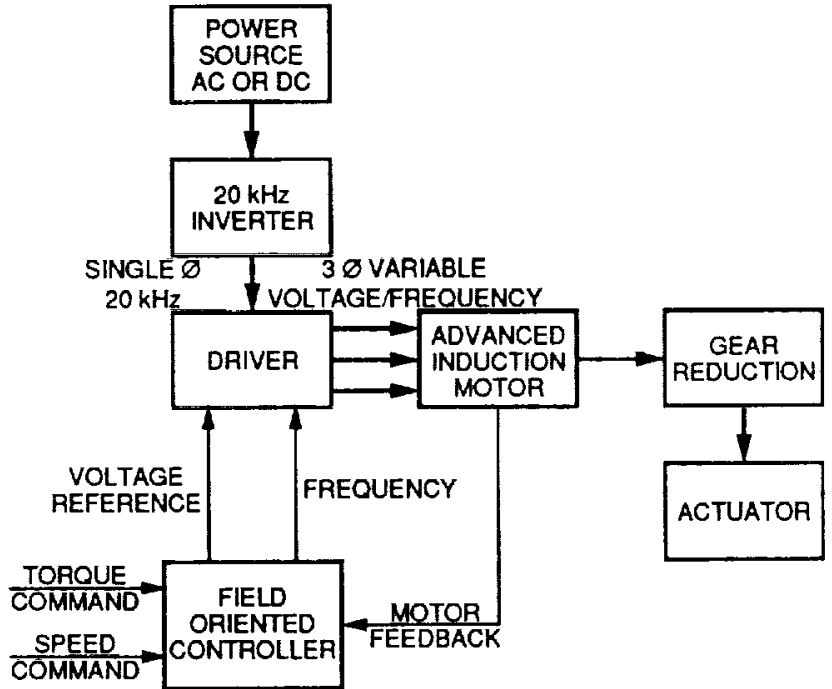

Figure 2. - Induction motor controller block diagram.

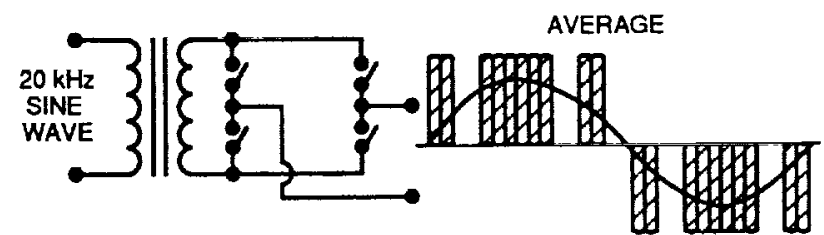

Figure 3. - Waveshape synthesis. 


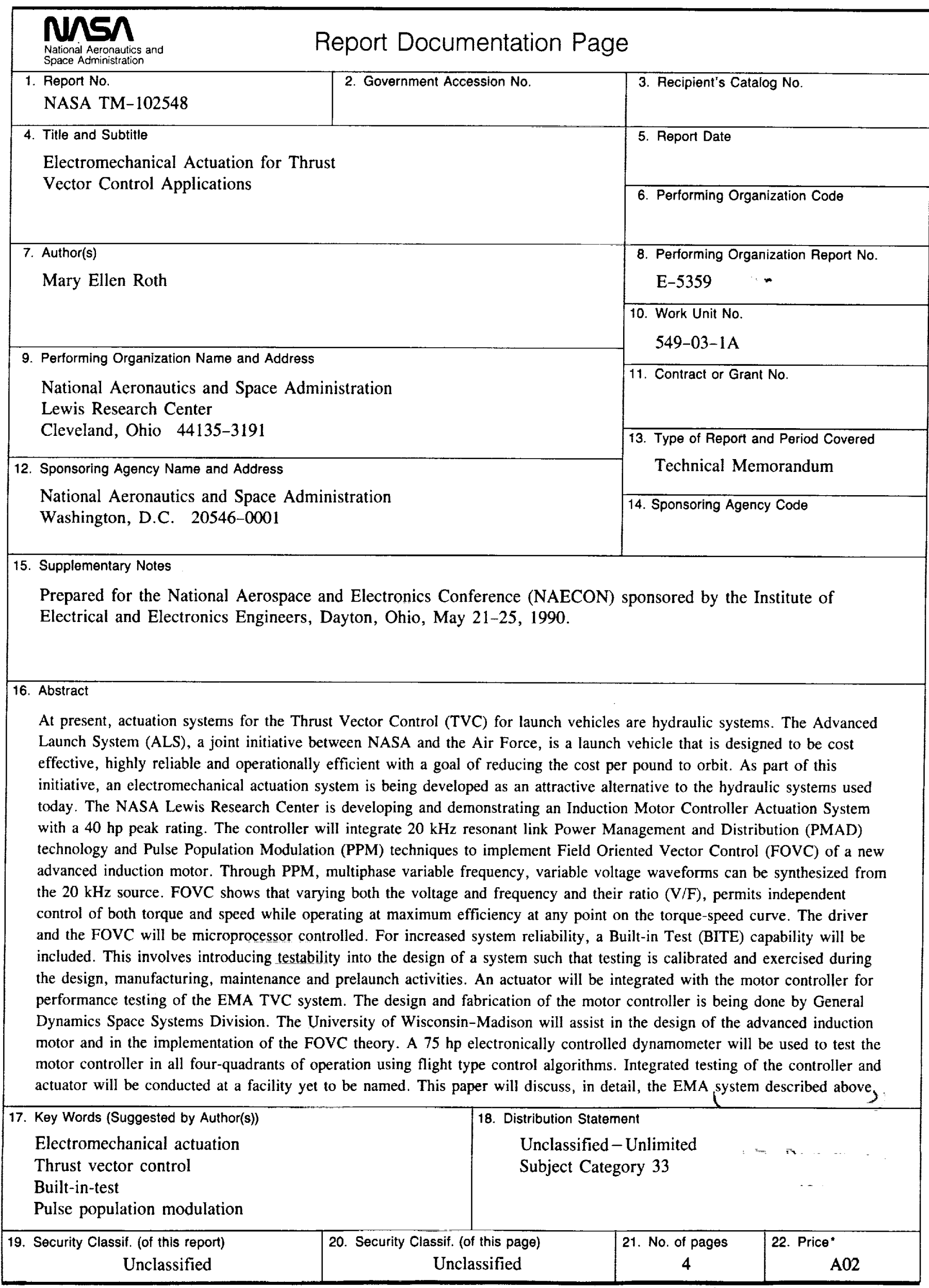

